\title{
Effects of emotional valence and three-dimensionality of visual stimuli on brain activation: An fMRI study
}

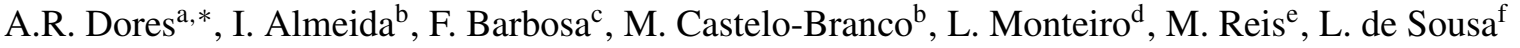 \\ and A. Castro Caldas ${ }^{\mathrm{g}}$ \\ ${ }^{a}$ Institute of Biomedical Sciences Abel Salazar, University of Porto (ICBAS-UP), Psychosocial Rehabilitation Lab, \\ Faculty of Psychology and Educational Sciences, University of Porto/School of Allied Health Sciences, \\ Polytechnic of Porto (LABRP, ESTSP-IPP/FPCEUP), Porto, Portugal \\ ${ }^{\mathrm{b}}$ Brain Imaging Network Portugal/National Association of Functional Brain Imaging (BING/ANIFC), \\ Coimbra, Portugal \\ ${ }^{\mathrm{c}}$ Faculty of Psychology and Educational Sciences, University of Porto (FPCEUP), Porto, Portugal \\ ${ }^{\mathrm{d}}$ Advanced Institute of Health Sciences - North (CESPU), Paredes, Portugal \\ ${ }^{\mathrm{e}}$ Service of Computerized Medical Imaging SA (SMIC), Porto, Portugal \\ ${ }^{\mathrm{f}}$ Institute of Biomedical Sciences Abel Salazar, University of Porto (ICBAS-UP), Porto, Portugal \\ ${ }^{\mathrm{g}}$ Institute of Health Sciences, Portuguese Catholic University (ICS-UCP), Lisboa, Portugal
}

\begin{abstract}
. However, main effects were also analyzed. regions. (scenarios' valence) and their interaction with three-dimensionality. (fMRI)

*Address for correspondence: Artemisa R. Dores, Escola Superior de Tecnologia da Saúde do Porto (ESTSP-IPP), R. Valente Perfeito, 322, 4400-330, Vila Nova de Gaia, Portugal. Tel.: +351 222061000; Fax: +351 222061001; E-mail: artemisa@estsp.ipp.pt.
\end{abstract}

BACKGROUND: Examining changes in brain activation linked with emotion-inducing stimuli is essential to the study of emotions. Due to the ecological potential of techniques such as virtual reality (VR), inspection of whether brain activation in response to emotional stimuli can be modulated by the three-dimensional (3D) properties of the images is important.

OBJECTIVE: The current study sought to test whether the activation of brain areas involved in the emotional processing of scenarios of different valences can be modulated by 3D. Therefore, the focus was made on the interaction effect between emotioninducing stimuli of different emotional valences (pleasant, unpleasant and neutral valences) and visualization types (2D, 3D).

METHODS: The effect of emotional valence and visualization types and their interaction were analyzed through a $3 \times 2$ repeated measures ANOVA. Post-hoc $t$-tests were performed under a ROI-analysis approach.

RESULTS: The results show increased brain activation for the 3D affective-inducing stimuli in comparison with the same stimuli in $2 \mathrm{D}$ scenarios, mostly in cortical and subcortical regions that are related to emotional processing, in addition to visual processing

CONCLUSIONS: This study has the potential of clarify brain mechanisms involved in the processing of emotional stimuli

Keywords: Emotional valence (pleasant, unpleasant, neutral), 3D/2D visual stimuli, functional Magnetic Resonance Imaging 


\section{Introduction}

Knowledge about emotions results largely from studies using images with emotional content in the context of laboratory experimentation. In constant development, the International Affective Picture System (IAPS; Lang, Bradley, \& Cuthbert, 1999) is one of the most widely used instruments for the selection of images. It now includes more than 900 emotional pictures in digital format, indexed by emotional valence, arousal and dominance, from various semantic categories: animals, landscapes, weapons, human facial expressions, mutilated bodies, etc. The emotional arousal and valence induced by the images have been measured through the Self-Assessment Maniquin scales (SAM; Lang, 1980).

However, the visualization of two-dimensional (2D) images as a method to induce emotions has some methodological limitations. Indeed, the laboratory investigation of emotional phenomena using simple slideshows containing drawings, words or images from the IAPS or similar systems has limited ecological validity and produces an attenuated emotional resonance in comparison to real emotional situations (Monteiro, Barbosa, \& Silvério, 2011). Thus, any development of these stimulus-materials making them closer to real emotional conditions is highly valuable to research. Still, stimuli must enable experimental manipulation of emotional responses in controlled laboratory sets. Adding three-dimensional (3D) properties to emotion-inducing stimuli is one method to achieve this purpose, making emotional responses more realistic.

Nowadays 3D softwares like Blender (Blender Foundation/Institute Amesterdan), 3ds Max (Autodesk, California) or Maya (Autodesk, California) can generate stereoscopic images of great realism. The stimuli developed with those technologies go beyond simple slide-like pictures. They are equally easy to handle and present greater ecological validity than traditional stimulus-material, precisely because they are closer to real-life stimuli (Dyck, Winbeck, Leiberg, Chen, \& Mathiak, 2010). For instance, Dyck and colleagues (2008) compared the recognition of 3D facial expressions (virtual expressions - avatars) with conventional photographs of human faces and found that sadness and fear were more easily recognized when presented in 3D. The work of Lee, Lim, Wiederhold, and Graham (2005) is another example. The authors investigated the effect of the two types of visualization on craving-inducing cues and concluded that participants pay more attention to $3 \mathrm{D}$ than to $2 \mathrm{D}$ stimuli. Newly developed 3D stimuli sets may thus represent a considerable benefit to emotion research performed in controlled laboratory environments. However, these new materials and their advantages over the conventional ones must be further investigated, both through self-report studies on the induced emotional states, and through studies on the respective neuronal correlates.

Functional neuroimaging supports the involvement of the amygdalae, fusiform gyri, inferior occipital gyri, orbital gyri, parahippocampal gyri, posterior cingulate cortex, and uncus as part of the neural systems in emotional processing (Adolphs, 2002, 2003; Adolphs, Damasio, Tranel, \& Damasio, 1996; Jehna et al., 2011; Lane et al., 1997; Whalen, Rauch, Etcoff, McInerney, Lee, \& Jenike, 1998). The role of the amygdalae in negative (Fanselow, \& Gale, 2003; LeDoux, 2003) and positive emotions has been recognized in literature (Murray, \& Ramage, 2000). Additionally, the role of the anterior insula (Craig, 2002, 2003; Critchley, Wiens, Rotshtein, Ohman, \& Dolan, 2004) and the anterior cingulated cortex (Decety, \& Jackson, 2004; Jackson, Brunet, Meltzoff, \& Decety, 2006) in the processing of emotionally salient contexts is well established. The contribution of the basal ganglia and cerebellar regions to human affective function is also recognized (Baumann, \& Mattingley, 2012; Lane et al., 1997; Paradiso et al., 1999).

In order to inspect the role of higher cortical mechanisms involved in emotional processing, in the current study we applied a paradigm in which subjects were involved in a long and repeated stimuli exhibition to create visual habituation. This procedure is intended to reduce the contribution of the low level visual processing mechanisms to the targeted contrasts, while emphasizing the relevance of the higher cortical mechanisms involved in emotional processing. We expected to find increased activation for the 3D affective-inducing stimuli in comparison with the same stimuli in 2D scenarios, mostly in cortical and subcortical regions that are related to emotional and high-level processing, in addition to visual processing regions.

\section{Materials and methods}

\subsection{Participants}

The sample consisted of 12 healthy male subjects who were recruited to participate in the study from rehabilitation institutions' databases in which they were registered as caregivers of former patients. The group's 
mean age was 26.58 years old $(\mathrm{SD}=5.16)$. Participants were all right handed (self-reported) and had no contraindiction for MRI, pathologies of the Central Nervous System (CNS), psychiatric disorders, trauma, or visual acuity deficits (assessed through a screening interview). All gave written informed consent to participate in this study. The protocol was approved by the Local Ethics Committee, and complies with the Declaration of Helsinki.

\subsection{Stimuli}

The stimuli were 3D Affective Inducing Scenarios (3DAIS) composed by 3D objects that were selected from our database, which comprises 131 objects. Sets of 15 stimuli-objects formed each scenario (Fig. 1), with one set per emotional valence - pleasant, unpleasant and neutral (to view the final scenarios and the stimuliobjects, please see Monteiro, Barbosa, \& Silvério, 2011). The 3D objects database had been previously developed to match the type of contents of the International Affective Picture System (IAPS; Lang, Bradley, \& Cuthbert, 1999) and equally validated with the Self-Assessment Maniquin scales (SAM; Lang, 1980) through rating procedures similar to those of Lang and colleagues' (1999). For our database, 214 individuals rated each of the 3D objects for emotional arousal (1 low, 9 - high) and valence (1 - unpleasant, 9 - pleasant) using the 9-point SAM scale (Monteiro, Barbosa, \& Silvério, 2011).

The stimuli were then selected and grouped according to the following criteria: (a) fifteen 3D objects receiving the highest scores in valence and arousal (valence $\geq 6.0$; arousal $\geq 4.0$ ) were included in the pleasant scenario; (b) fifteen 3D objects receiving the lowest scores in valence and the highest in arousal (valence $\leq 4.0$; arousal $\geq 4.0$ ) were included in the unpleasant scenario; (c) fifteen stimuli with intermediate values in valence and low scores in arousal $(4.5 \leq$ valence $\leq 5.5$, arousal $\leq 3.0$ ) were included in the neutral scenario.

Scenarios occupying a visual angle of $32^{\circ} \times 22^{\circ}$ were presented in a $150 \times 100 \mathrm{~cm}$ screen with a stimulation unit (laptop computer running Windows Vista) connected to a rear projection system (multimedia projector XGA $1024 \times 768$ pixels and 2200 ANSI lumens).

A $1.5 \mathrm{~T}$ scanner (MAGNETON, Sonata, Siemens) with a gradient of Maximum Amplitude $40 \mathrm{mT} / \mathrm{m}$, Minimum Rise Time $200 \mu \mathrm{s}$, Maximum Slew Rate $200 \mathrm{~T} / \mathrm{m} / \mathrm{s}$ was used for the MR scanning. Inside the scanner, the stimuli were back projected by means of a radiofrequency head coil mounted mirror. Passive glasses (Zone, 2005) were used for the 3D visualization, which was created through an anaglyph image technique.

\subsection{Design and procedures}

Visualization type (2D, 3D) and emotional valence (pleasant, unpleasant and neutral scenarios) were used as factors in a within-subjects $3 \times 2$ experimental design. The experiment consisted of a single session of fMRI scanning. The presentation of the $2 \mathrm{D}$ and of the $3 \mathrm{D}$ scenarios was counterbalanced in a block-design paradigm with two fMRI runs for the two visualization types, respectively. Each run had the total duration of $4^{\prime} 4$ ". The run began with $4 \mathrm{sec}$ of no stimulation (then discarded) so that the MR signal could reach the equilibrium point.

Participants were given the opportunity and the necessary amount of time to put on or take off the anaglyph glasses between runs, so the initial visualization conditions (the 2D or 3D types) were matched. Each run consisted of three cycles of rest and activation with no interval between cycles. The three cycles corresponded to the three emotional valences, also counterbalanced to control for order effects. During the resting periods a fixation cross was displayed for $40 \mathrm{sec}$, followed
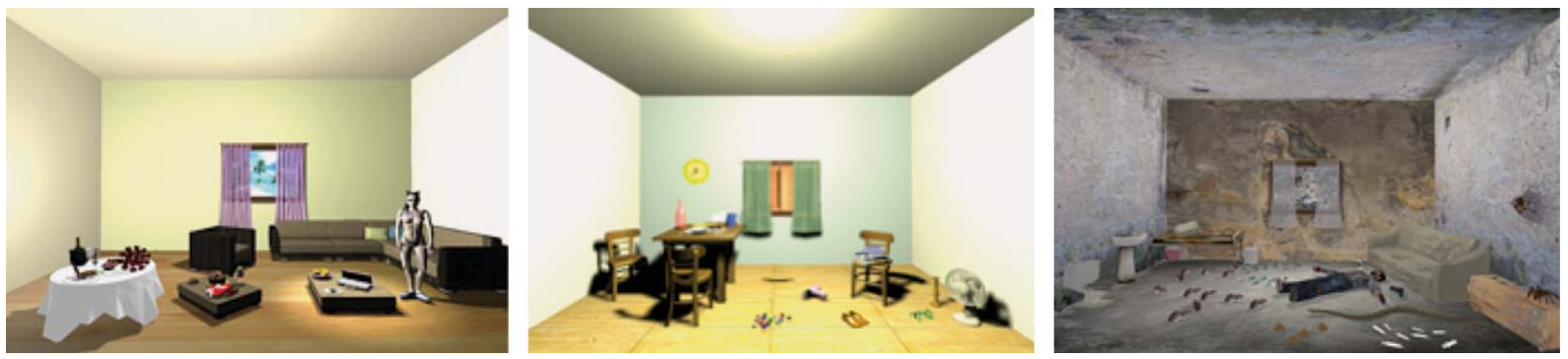

Fig. 1. Emotion-inducing scenarios of different valences (pleasant, neutral, unpleasant valences) projected in 2D and 3D. 
immediately by one of the scenarios, displayed for another $40 \mathrm{sec}$.

Participants were instructed to avoid movements, to keep their eyes open during the whole session, and to pay attention to the image projected on the screen.

\subsection{Data acquisition}

For functional imaging a gradient-echo $\mathrm{T} 2 *_{-}$ weighted Echo-Planar Imaging (EPI) sequence ( $\mathrm{TE}=50 \mathrm{~ms}$, flip angle $\left.90^{\circ}, \mathrm{TR}=4 \mathrm{~s}\right)$ was used to measure the BOLD (blood oxygenation level dependent) effect (Ogawa, Lee, Kay, \& Tank, 1990). The Field of View (FOV) was $240 \times 240 \mathrm{~mm}^{2}$ with a $64 \times 64$ matrix resulting in an effective resolution of $3.75 \mathrm{~mm} \times 3.75 \mathrm{~mm} \times 3 \mathrm{~mm}$ (Thk). Sixty volumes with 36 slices each were acquired in axial orientation, with slices being aligned parallel to the anterior-posterior commissure. The slice thickness was $3 \mathrm{~mm}$ with a gap of $25 \%$. For anatomic reference, a high-resolution MPRAGE T1-weighted scan was acquired for each participant with the following parameters: $\mathrm{TR}=2 \mathrm{~s}, \mathrm{TE}=3.69 \mathrm{~ms}, 256 \times 256$ matrix, FOV $240 \times 240 \mathrm{~mm}^{2}$, slice thickness of $1 \mathrm{~mm}$ leading to an effective resolution of $0.9 \times 0.9 \times 1 \mathrm{~mm}$ ).

\subsection{Data analysis}

Preprocessing of functional data, including slice time correction, 3D motion correction, spatial smoothing and temporal filtering, was conducted using BrainVoyager QX 2.3 (2011, Brain Innovation, Netherlands). Functional and anatomical scans of the data were coregistered and normalized to Talairach space. Data were analyzed through a GLM-based random effects procedure. Resulting whole brain activation maps for all contrasts were thresholded at a $p$-value $<0.001$ (uncor- rected). Clusters were only accepted if consisting of at least seven contiguous voxels.

The effects of emotional valence (pleasant, unpleasant and neutral scenarios), the visualization type (2D and 3D types), and their interaction were computed through a $3 \times 2$ repeated measures ANOVA. Post-hoc ttests were performed under a ROI-analysis approach on the clusters for which the ANOVA showed significant interaction effects. Talairach Client v2.4.2 was used to convert coordinates of the regions significantly activated into Talairach labels as long as these were within the defined minimum voxel size (Lancaster et al., 1997, 2000).

\section{Results}

The ANOVA revealed an interaction effect between emotional valence (pleasant, unpleasant and neutral scenarios) and visualization types (2D and 3D types) in several visual and emotion related areas. Table 1 lists the areas that were activated for this effect.

Table 2 shows the post-hoc tests comparing emotional valences within visualization types (unpleasant vs. pleasant vs. neutral scenarios within the 2D type, and unpleasant vs. pleasant vs. neutral scenarios within the 3D type) and visualization types within emotional valences (3D vs. 2D types within the pleasant scenario, $3 \mathrm{D}$ vs. $2 \mathrm{D}$ types within the unpleasant scenarios, and $3 \mathrm{D}$ vs. $2 \mathrm{D}$ types within the neutral scenarios).

Concerning the main effects, results for the factor emotional valence are presented in Table 3. Volumesof-interest were created for each cluster (minimum size $=7$ voxels) after a $3 \times 2$ ANOVA, with post-hoc $t$-tests being performed under a ROI-analysis approach.

The areas responding to the main effect of visualization type are reported in Table 4.

Table 1

Anatomic location, brain hemisphere, brain areas and their Talairach coordinates detected through $3 \times 2$ ANOVA analysis: Interaction effect of visualization effects and valence

\begin{tabular}{|c|c|c|c|c|c|c|c|c|}
\hline \multirow[t]{2}{*}{ Anatomic Location } & \multirow[t]{2}{*}{$\mathrm{BH}$} & \multirow[t]{2}{*}{ BA } & \multicolumn{3}{|c|}{ Coordinates } & \multirow[t]{2}{*}{$F$} & \multirow[t]{2}{*}{$p$} & \multirow[t]{2}{*}{ Size* } \\
\hline & & & $\mathrm{x}$ & $\mathrm{y}$ & $\mathrm{z}$ & & & \\
\hline Uncus & $\mathrm{L}$ & 36 & -19.0 & -8.0 & -27.0 & 18.506 & 0.000019 & 31 \\
\hline Postcentral Gyrus & $\mathrm{R}$ & 3 & 41.0 & -20.0 & 51.0 & 13.294 & 0.000164 & 20 \\
\hline Middle Frontal Gyrus & $\mathrm{R}$ & 46 & 53.0 & 28.0 & 24.0 & 16.225 & 0.000047 & 15 \\
\hline Declive & $\mathrm{R}$ & & 35.0 & -62.0 & -15.0 & 16.723 & 0.000038 & 15 \\
\hline Cerebellar Tonsil & $\mathrm{L}$ & & -25.0 & -41.0 & -42.0 & 15.584 & 0.000061 & 13 \\
\hline Cingulate Gyrus & $\mathrm{R}$ & 24 & 20.0 & -8.0 & 39.0 & 15.697 & 0.000058 & 10 \\
\hline Lentiform Nucleus & $\mathrm{L}$ & & -31.0 & -14.0 & 6.0 & 15.336 & 0.000067 & 9 \\
\hline
\end{tabular}

Note: $\mathrm{BH}=$ Brain Hemisphere; BA = Brodmann's area; $\mathrm{L}=$ left; $\mathrm{R}=$ right; *number of voxels. Clusters were only considered if seven or more contiguous voxels were activated. 
Table 2

Random effects analysis of contrasts: Post-hoc t-tests to identify (a) valence effects (Pl, Unpl and N valences) within visualization type (2D, 3D types) and (b) visualization effects within valence

\begin{tabular}{|c|c|c|c|c|c|c|c|}
\hline \multirow[t]{2}{*}{ Contrast } & \multirow[t]{2}{*}{ Df } & \multirow[t]{2}{*}{$t$} & \multirow[t]{2}{*}{$p$} & \multicolumn{3}{|c|}{ Coordinates } & \multirow[t]{2}{*}{ Anatomic Location } \\
\hline & & & & $\mathrm{x}$ & $\mathrm{y}$ & $\mathrm{z}$ & \\
\hline \multicolumn{8}{|c|}{ Valence effects within visualization type (a) } \\
\hline 2D Unpl > 2D Pl & 11 & 4.554 & 0.001 & -19.0 & -8.0 & -27.0 & Uncus \\
\hline $2 \mathrm{D} \mathrm{Pl}>2 \mathrm{D} \mathrm{N}$ & 11 & 3.499 & 0.005 & 41.0 & -20.0 & 51.0 & Postcentral Gyrus \\
\hline 2D Unpl > 2D N & 11 & 5.859 & 0.000 & & & & \\
\hline 3D Pl>3D N & 11 & 3.483 & 0.005 & 53.0 & 28.0 & 24.0 & Middle Frontal Gyrus \\
\hline 2D Unpl > 2D N & 11 & 3.830 & 0.003 & -37.0 & -38.0 & -36.0 & Cerebellar Tonsil \\
\hline $2 \mathrm{D} \mathrm{Pl}>2 \mathrm{D} \mathrm{N}$ & 11 & 3.391 & 0.006 & -25.0 & -41.0 & -42.0 & \\
\hline $2 \mathrm{D} \mathrm{Pl}>2 \mathrm{D} \mathrm{N}$ & 11 & 3.400 & 0.006 & 20.0 & -8.0 & 39.0 & Cingulate Gyrus \\
\hline 2D Unpl > 2D N & 11 & 4.015 & 0.002 & & & & \\
\hline \multicolumn{8}{|c|}{ Visualization effects within valence (b) } \\
\hline $3 \mathrm{D}>2 \mathrm{D} \mathrm{Pl}$ & 11 & 2.985 & 0.012 & 35.0 & -62.0 & -15.0 & Declive \\
\hline $3 \mathrm{D}<2 \mathrm{D} \mathrm{N}$ & 11 & 3.611 & 0.004 & -13.0 & -56.0 & -36.0 & Cerebellar Tonsil \\
\hline
\end{tabular}

Note: $\mathrm{Pl}=$ pleasant; $\mathrm{Unpl}=$ unpleasant and $N=$ neutral. The results are corrected for multiple comparisons, (a) $p=0.05 / 6<0.008$, (b) $p=0.05 / 3$ $<0.017$.

Table 3

Anatomic location, brain hemisphere, brain areas and their Talairach coordinates in which seven or more voxels were activated, detected through $3 \times 2$ ANOVA analysis and post-hoc $t$-tests: Main effect of emotional valence

\begin{tabular}{|c|c|c|c|c|c|c|c|c|c|c|c|c|}
\hline \multirow[t]{2}{*}{ Anatomic Location } & \multirow[t]{2}{*}{$\mathrm{BH}$} & \multirow[t]{2}{*}{ BA } & \multicolumn{3}{|c|}{ Coordinates } & \multirow[t]{2}{*}{$F$} & \multirow[t]{2}{*}{$p$} & \multirow[t]{2}{*}{ Size* } & \multicolumn{4}{|c|}{ Contrast } \\
\hline & & & $\mathrm{x}$ & $\mathrm{y}$ & $\mathrm{z}$ & & & & & $t$ & df & $p$ \\
\hline \multirow[t]{2}{*}{ Paracentral Lobule } & \multirow[t]{2}{*}{$\mathrm{L}$} & \multirow[t]{2}{*}{5} & \multirow[t]{2}{*}{-10.0} & \multirow[t]{2}{*}{-41.0} & \multirow[t]{2}{*}{60.0} & \multirow[t]{2}{*}{18.957} & \multirow[t]{2}{*}{0.000016} & \multirow[t]{2}{*}{20} & Unpl $>\mathrm{N}$ & 5.084 & 11 & 0.000 \\
\hline & & & & & & & & & Unpl $>\mathrm{Pl}$ & 3.611 & 11 & 0.004 \\
\hline \multirow[t]{4}{*}{ Inferior Parietal Lobule } & \multirow[t]{2}{*}{$\mathrm{R}$} & \multirow[t]{2}{*}{40} & \multirow[t]{2}{*}{41.0} & \multirow[t]{2}{*}{-47.0} & \multirow[t]{2}{*}{55.0} & \multirow[t]{2}{*}{12.306} & \multirow[t]{2}{*}{0.000259} & \multirow[t]{2}{*}{15} & $\mathrm{Pl}>\mathrm{N}$ & 3.572 & 11 & 0.004 \\
\hline & & & & & & & & & Unpl > N & 4.496 & 11 & 0.001 \\
\hline & \multirow[t]{2}{*}{$\mathrm{R}$} & \multirow[t]{2}{*}{40} & \multirow[t]{2}{*}{47.0} & \multirow[t]{2}{*}{-29.0} & \multirow[t]{2}{*}{48.0} & \multirow[t]{2}{*}{14.521} & \multirow[t]{2}{*}{0.000095} & \multirow[t]{2}{*}{7} & Unpl $>\mathrm{N}$ & 3.759 & 11 & 0.003 \\
\hline & & & & & & & & & Unpl $>\mathrm{Pl}$ & 4.637 & 11 & 0.001 \\
\hline Precuneus & $\mathrm{L}$ & 7 & -31.0 & -44.0 & 51.0 & 14.190 & 0.000110 & 11 & $\mathrm{Pl}>\mathrm{N}$ & 3.515 & 11 & 0.005 \\
\hline & & & & & & & & & Unpl $>\mathrm{N}$ & 2.820 & 11 & 0.017 \\
\hline & & & & & & & & & Unpl > Pl & 4.458 & 11 & 0.001 \\
\hline Superior Temporal Gyrus & $\mathrm{R}$ & 22 & 62.0 & -35.0 & 9.0 & 13.985 & 0.000120 & 9 & $\mathrm{Pl}>\mathrm{N}$ & 2.985 & 11 & 0.002 \\
\hline & & & & & & & & & Unpl $>\mathrm{N}$ & 5.056 & 11 & 0.000 \\
\hline & & & & & & & & & Unpl $>\mathrm{Pl}$ & 3.274 & 11 & 0.007 \\
\hline Middle Frontal Gyrus & $\mathrm{R}$ & 10 & 32.0 & 34.0 & 18.0 & 14.519 & 0.000095 & 9 & Unpl $>\mathrm{N}$ & 4.441 & 11 & 0.001 \\
\hline & & & & & & & & & Unpl > Pl & 4.878 & 11 & 0.000 \\
\hline Postcentral Gyrus & $\mathrm{R}$ & 3 & 62.0 & -11.0 & 24.0 & 14.828 & 0.000084 & 8 & Unpl > N & 5.740 & 11 & 0.000 \\
\hline & & & & & & & & & Unpl > Pl & 5.386 & 11 & 0.000 \\
\hline
\end{tabular}

Note: $\mathrm{BH}=$ Brain Hemisphere; $\mathrm{BA}=$ Brodmann's area; $\mathrm{Pl}=$ pleasant; $\mathrm{L}=$ left; $\mathrm{R}=$ right; $N=$ neutral; Unpl = unpleasant; *number of voxels. The results are corrected for multiple comparisons.

\section{Discussion}

In the current study we used 3D versus 2D stimuli charged with different emotional values. Our purpose was twofold: (1) to test whether the activation of brain areas involved in the visual and emotional processing of scenarios with different valence values could be modulated by three-dimensionality and (2) to study the role of cortical mechanisms involved in emotional processing. Therefore, we compared BOLD signal changes in both emotional and visual areas during presentation of VR scenarios in two different visualization types (2D and $3 \mathrm{D}$ types). In addition, we looked at other frontal and temporal regions, known to be involved in higher cognitive functions.

The most interesting finding refer to the interaction effect between emotional valence and visualization type in areas responsible for emotional and cognitive processing. As expected, we found increased activation in cortical areas, such as the postcentral gyrus and the middle frontal gyrus, but only with pleasant and unpleasant scenarios. The involvement of these regions has been previously identified in neuroimaging studies of emotion (Damasio et al., 2000, George, Ketter, Parekh, Herscovitch, \& Post, 1996; Lane, Chua, \& Dolan, 1999), and the activated prefrontal region may reflect 
Table 4

Anatomic location, brain hemisphere, brain areas and their Talairach coordinates in which seven or more voxels were activated, detected through $3 \times 2$ ANOVA analysis and post-hoc $t$-tests: Main effect of visualization type

\begin{tabular}{|c|c|c|c|c|c|c|c|c|c|c|c|c|}
\hline \multirow[t]{2}{*}{ Anatomic Location } & \multirow[t]{2}{*}{ BH } & \multirow[t]{2}{*}{ BA } & \multicolumn{3}{|c|}{ Coordinates } & \multirow[t]{2}{*}{$F$} & \multirow[t]{2}{*}{$p$} & \multirow[t]{2}{*}{ Size* } & \multicolumn{4}{|c|}{ Contrast } \\
\hline & & & $\mathrm{x}$ & $\mathrm{y}$ & $\mathrm{z}$ & & & & & $t$ & df & $P$ \\
\hline Lentiform Nucleus & $\mathrm{L}$ & & -16.0 & -2.0 & -6.0 & 43.408 & 0.000039 & 38 & $3 \mathrm{D}>2 \mathrm{D}$ & 6.750 & 11 & 0.000 \\
\hline Fusiform Gyrus & $\mathrm{L}$ & 20 & -55.0 & -35.0 & -21.0 & 45.157 & 0.000033 & 25 & $3 \mathrm{D}>2 \mathrm{D}$ & 6.372 & 11 & 0.000 \\
\hline \multirow[t]{2}{*}{ Precentral Gyrus } & $\mathrm{L}$ & 6 & -49.0 & -2.0 & 33.0 & 47.479 & 0.000026 & 22 & $3 \mathrm{D}>2 \mathrm{D}$ & 3.901 & 11 & 0.002 \\
\hline & $\mathrm{R}$ & 6 & 32.0 & -14.0 & 54.0 & 32.910 & 0.000131 & 10 & $3 \mathrm{D}>2 \mathrm{D}$ & 6.085 & 11 & 0.000 \\
\hline Cuneus & $\mathrm{L}$ & 17 & -19.0 & -95.0 & 0.0 & 48.263 & 0.000024 & 20 & $3 \mathrm{D}>2 \mathrm{D}$ & 3.571 & 11 & 0.004 \\
\hline Superior Temporal Gyrus & $\mathrm{L}$ & 42 & -52.0 & -32.0 & 15.0 & 35.788 & 0.000092 & 16 & $3 \mathrm{D}>2 \mathrm{D}$ & 5.369 & 11 & 0.000 \\
\hline Precuneus & $\mathrm{L}$ & 31 & -13.0 & -62.0 & 21.0 & 32.412 & 0.000140 & 14 & $3 \mathrm{D}>2 \mathrm{D}$ & 5.440 & 11 & 0.000 \\
\hline Middle Frontal Gyrus & $\mathrm{L}$ & 9 & -46.0 & 31.0 & 30.0 & 26.381 & 0.000325 & 12 & $3 \mathrm{D}>2 \mathrm{D}$ & 5.490 & 11 & 0.000 \\
\hline Inferior Frontal Gyrus & $\mathrm{R}$ & 45 & 50.0 & 22.0 & 12.0 & 29.854 & 0.000197 & 7 & $3 \mathrm{D}>2 \mathrm{D}$ & 5.346 & 11 & 0.000 \\
\hline Superior Frontal Gyrus & $\mathrm{R}$ & 6 & 5.0 & 7.0 & 57.0 & 30.968 & 0.000169 & 7 & $3 \mathrm{D}>2 \mathrm{D}$ & 4.141 & 11 & 0.002 \\
\hline Superior Temporal Gyrus & $\mathrm{R}$ & 38 & 47.0 & 7.0 & -18.0 & 29.348 & 0.000211 & 7 & $3 \mathrm{D}>2 \mathrm{D}$ & 4.572 & 11 & 0.001 \\
\hline Cuneus & $\mathrm{L}$ & 17 & -16.0 & -80.0 & 6.0 & 29.755 & 0.000199 & 7 & $3 \mathrm{D}>2 \mathrm{D}$ & 5.417 & 11 & 0.000 \\
\hline Sub-Gyral & $\mathrm{L}$ & 40 & -31.0 & -44.0 & 33.0 & 29.261 & 0.000214 & 7 & $3 \mathrm{D}>2 \mathrm{D}$ & 4.759 & 11 & 0.001 \\
\hline
\end{tabular}

Note: $\mathrm{BH}=$ Brain Hemisphere; BA = Brodmann's area; $\mathrm{L}=$ left; $\mathrm{R}=$ right; *number of voxels. The results are corrected for multiple comparisons.

the presence of high-level cognitive interpretations (Ochsner et al., 2009). We expected that the paradigm we used, which consisted of a long and repeated stimuli exhibition, would elicit these areas. The results also show the activation of subcortical structures, such as some components of the cerebellum (i.e., the declive and cerebellar tonsil) and some components of the basal ganglia (i.e., the lentiform nucleus, which refers to the globus pallidus and the putamen) (Baumann, \& Mattingley, 2012; Lane et al., 1997; Paradiso et al., 1999). The cerebellum has only recently started to be recognized as part of the neural networks responsible for emotional processing (Baumann, \& Mattingley, 2012; Tettamanti et al., 2012), although its role on emotions is still unclear. In addition to these regions, we found the activation of portions of the limbic lobe (i.e., the uncus (Lawrence et al., 2004) and cingulated gyrus (Decety, \& Jackson, 2004; Jackson, Brunet, Meltzoff, \& Decety, 2006), traditionally recognized as being especially involved in emotional processes. Considering that current neurobiological models of emotion and several studies (Baumann, \& Mattingley, 2012; Kober et al., 2008; Tettamanti et al., 2012) recognize the mediation of both cortical and subcortical areas in emotional processing, these results are consistent with the literature.

Concerning the valence effects within visualization type, the results allowed us to understand the relation between the different emotional valences, with the direction of the contrasts occurring as expected, i.e., unpleasant $>$ pleasant $>$ neutral valence for the $2 \mathrm{D}$ visualization type, but only pleasant $>$ neutral for the $3 \mathrm{D}$ visualization type. The direction of the contrasts became clearer when we examined the emotion valence independently of the visualization type (the main effect of emotion valence). In this case, our fMRI data are in agreement with the well-known unpleasant emotion bias. In fact, the unpleasant scenarios produced higher activation compared to pleasant and neutral ones in all the referred brain regions, namely the paracentral lobule, inferior parietal lobule, precuneus, superior temporal gyrus, middle frontal gyrus and postcentral gyrus. In some of these areas (inferior parietal lobule, precuneus, superior temporal gyrus) we also observed that pleasant scenarios elicited increased activation, compared to neutral ones.

Concerning the visualization effects within valence, post-hoc analyses revealed that 3D produced greater activation than $2 \mathrm{D}$ scenarios in the declive region, but only for the pleasant valence. Unexpectedly, the opposite effect was found in the cerebellar tonsil for the neutral scenario. Regarding the main effect of visualization type (independently of emotional valence), the 3D scenarios consistently produced greater activation in all the brain regions, as compared to the $2 \mathrm{D}$ scenarios.

Finally, the results also show the influence of threedimensional scenarios on visual processing, although this was not the main focus of this study. Specifically, 3D scenarios produced an increased activation in regions that are part of the anterior intraparietal area (Precuneus [BA 7, 31] and Sub-Gyral [BA 40]) and inferotemporal cortex (Fusiform Gyrus [BA 20]). These results are consistent with the literature that reports the involvement of these regions in visual processing of 3D stimuli. An example of this phenomenon is the participation of the AIP (anterior intraparietal area BA40) 
neurons in the perception of 3D contours and surfaces (Theys, Srivastava, van Loon, Goffin, \& Janssen, 2012), or the involvement of the IT cortex in the perception of binocular disparity (Janssen, Vogels, \& Orban, 2000; Uka, Tanabe, Watanabe, \& Fujita, 2005; Verhoef, Vogels, \& Janssen, 2012).

The observed activation of the Precuneus (BA 7) also supports the role of 3D in stereopsis, since this area has been related with this function (Fortin, Ptito, Faubert, $\&$ Ptito, 2002). In our study this region was more active during the $3 \mathrm{D}$ than during the 2D scenario. Moreover, part of the primary visual cortex (cuneus or BA 17) showed increased activity.

Overall, our results showed increased brain activation for the 3D affective-inducing stimuli in comparison with the same stimuli in 2D scenarios. This effect was observed mostly in cortical and subcortical regions that are related to emotional processing, in addition to visual and other regions involved in high-level cognitive processing. It is noteworthy that the contrast and light of the scenarios was not fully controlled and this could have induced differences between the neutral, pleasant and unpleasant scenarios that influenced participant's cerebral activation.

\section{Conclusions}

In the current study we used 3D versus 2D stimuli charged with different emotional values in order to test the impact of two different visualization types on brain regions involved in visual and emotional processing. These preliminary fMRI results suggest that 3D scenarios may be best suited for developing methodological paradigms for experimental research in the field of emotions. They may represent an advantage when compared to $2 \mathrm{D}$ stimuli, as they bring more realism into laboratorial settings.

\section{Acknowledgments}

This research project was funded by the FCT - Portuguese Foundation for Science and Technology (Ref. SFRH/BD/28510/2006), co-funded by FEDER funds through COMPETE - Operational Programme 'Thematic Factors of Competitiveness, and also co-funded by the BIAL Foundation (Ref. 94/08). The authors also wish to thank Eduardo Ribeiro, Ernesto Pinho, Marcos Freitas, and SMIC, for their cooperation in the acquisition of the fMRI data.

\section{Declaration of interest}

There are no potentially competing interests to be declared.

\section{References}

Adolphs, R. (2002). Neural systems for recognizing emotion. Current Opinion in Neurobiology, 12(2), 169-177.

Adolphs, R. (2003). Cognitive neuroscience of human social behaviour. Nature Reviews Neuroscience, 4, 165-178.

Adolphs, R., Damasio, H., Tranel, D., \& Damasio, A. R. (1996). Cortical systems for the recognition of emotion in facial expressions. Journal of Neuroscience, 16, 7678-7687.

Baumann, O., \& Mattingley, J. B. (2012). Functional topography of primary emotion processing in the human cerebellum. Neuroimage, 61(4), 805-811.

Craig, A. D. (2002). How do you feel? Interoception: The sense of the physiological condition of the body. Nature Reviews Neuroscience, 3, 655-666.

Craig, A. D. (2003). Interoception: The sense of the physiological condition of the body. Current Opinion in Neurobiology, 13(4), 500-505.

Critchley, H. D., Wiens, S., Rotshtein, P., Ohman, A., \& Dolan, R. J. (2004). Neural systems supporting interoceptive awareness. Nature Neuroscience, 7(2), 189-195.

Damasio, A. R., Grabowski, T. J., Bechara, A., Damasio, H., Ponto, L. L. B., Parvizi, J., \& Hichwa, R. D. (2000). Subcortical and cortical brain activity during the feeling of self-generated emotions. Nature Neuroscience, 3(10), 1049-1056.

Decety, J., \& Jackson, P. L. (2004). The functional architecture of human empathy. Behavioral and Cognitive Neuroscience Reviews, 3, 71-100.

Dyck, M., Winbeck, M., Leiberg, S., Chen, Y., Gur, R., \& Mathiak, K. (2008). Recognition profile of emotions in natural and virtual faces. PLoS One, 3(11), 3628.

Dyck, M., Winbeck, M., Leiberg, S., Chen, Y., \& Mathiak, K. (2010). Virtual faces as a tool to study emotion recognition deficits in schizophrenia. Psychiatry Research, 179(3), 247-252.

Fanselow, M. S., \& Gale, G. D. (2003). The amygdala, fear, and memory. Annals of the New York Academy of Sciences, 985, 125134.

Fortin, A., Ptito, A., Faubert, J., \& Ptito, M. C. A. (2002). Cortical areas mediating stereopsis in the human brain: A PET study. Neuroreport, 13(6), 895-898.

George, M. S., Ketter, T. A., Parekh, P. I., Herscovitch, P., \& Post, R. M. (1996). Biol. Psychiatry, 40, 859-871.

Jackson, P. L., Brunet, E., Meltzoff, A. N., \& Decety, J. (2006). Empathy examined through the neural mechanisms involved in imagining how I feel versus how you feel pain: An event-related fMRI study. Neuropsychologia, 44, 752-761.

Janssen, P., Vogels, R., \& Orban, G. A. (2000). Selectivity for 3D shape that reveals distinct areas within macaque inferior temporal cortex. Science, 288, 2054-2056.

Jehna, M., Neuper, C., Ischebeck, A., Loifelder, M., Ropele, S., Langhammer, C. et al. (2011). The functional correlates of face perception and recognition of emotional facial expressions as evidenced by fMRI. Brain Research, 1393, 73-83. 
Kober, H., Barrett, L. F., Joseph, J., Bliss-Moreau, E., Lindquist, K., \& Wager, T. D. (2008). Functional grouping and cortical-subcortical interactions in emotion: A meta-analysis of neuroimaging studies. Neuroimage, 42(2), 998-1031.

Lancaster, J. L., Woldorff, M. G., Parsons, L. M., Liotti, M., Freitas, C. S., Rainey, L. et al. (2000). Automated Talairach Atlas labels for functional brain mapping. Human Brain Mapping, 10, 120-131.

Lancaster, J. L., Rainey, L. H., Summerlin, J. L., Freitas, C. S., Fox, P. T., Evans, A. C. et al. (1997). Automated labeling of the human brain: A preliminary report on the development and evaluation of a forward-transform method. Human Brain Mapping, 5, 238-242.

Lane, R. D., Chua, P. M., \& Dolan, R. J. (1999). Common effects of emotional valence, arousal and attention on neural activation during visual processing of pictures. Neuropsychologia, 37(9), 989-997.

Lane, R. D., Reiman, E. M., Bradley, M. M., Lang, P. J., Ahern, G. L., Davidson, R. J., \& Schwartz, G. E. (1997). Neuroanatomical correlates of pleasant and unpleasant emotion. Neuropsychologia, 35(11), 1437-1444.

Lang, P. J. (1980). Behavioral treatment and biobehavioral assessment: Computer applications. In: J. Sidowski, J. Johnson \& T. Williams (Eds.), Technology in mental health care delivery systems (pp. 119-137). Ablex, Norwood, NJ.

Lang, P. J., Bradley, M. M., \& Cuthbert, B. N. (1999). International affective picture system (IAPS): Affective ratings of pictures and instruction manual Center for Research in Psychophysiology, University of Florida, Gainesville, FL.

Lawrence, N. S., Williams, A. M., Surguladze, S., Giampietro, V., Brammer, M. J., Andrew, C. et al. (2004). Subcortical and ventral prefrontal cortical neural responses to facial expressions distinguish patients with bipolar disorder and major depression. Biological Psychiatry, 55, 578-587.

LeDoux, J. (2003). The emotional brain, fear, and the amygdala. Cellular and Molecular Neurobiology, 23, 727-738.

Lee, J. H., Lim, Y., Wiederhold, B. K., \& Graham, S. J. (2005). A functional magnetic resonance imaging (fMRI) study of cue-induced smoking craving in virtual environments. Applied Psychophysiology and Biofeedback, 30(3), 195-204.
Monteiro, L., Barbosa, F., \& Silvério, J. (2011). Dados normativos da indução de emoções em ambientes de realidade virtual. Saúde Mental, 13(6), 10-20.

Murray, L. L., \& Ramage, A. E. (2000). Assessing the executive function abilities of adults with neurogenic communication disorders. Seminars in Speech and Language, 21(2), 153-167.

Ochsner, K. N., Ray, R. R., Hughes, B., McRae, K., Cooper, J. C., Weber, J., et al. (2009). Bottom-Up and Top-Down Processes in Emotion Generation: Common and Distinct Neural Mechanisms. Psychological Science, 20(11), 1322-1331.

Ogawa, S., Lee, T. M., Kay, A. R., \& Tank, D. W. (1990). Brain magnetic resonance imaging with contrast dependent on blood oxygenation. Proceedings of the National Academy of Sciences of the United States of America, 87(24), 9868-9872.

Paradiso, S., Jhonson, D. L., Andreasen, N. C., O'Leary, D. S., Watkins, G. L., Ponto, L.L. et al. (1999). Cerebral blood flow changes associated with attribution of emotional valence to pleasant, unpleasant, and neutral visual stimuli in a PET study of normal subjects. American Journal of Psychiatry, 156, 16181629.

Tettamanti, M., Rognoni, E., Cafiero, R., Costa, T., Galati, D., \& Perani, D. (2012). Distinct pathways of neural coupling for different basic emotions. Neuroimage, 59(2), 1804-1817.

Theys, T., Srivastava, S., van Loon, J., Goffin, J., \& Janssen, P. (2012). Selectivity for three-dimensional contours and surfaces in the anterior intraparietal area. Journal of Neurophysiology, 107, 995-1008.

Uka, T., Tanabe, S., Watanabe, M., \& Fujita, I. (2005). Neural correlates of fine depth discrimination in monkey inferior temporal cortex. Journal of Neuroscience, 25, 10796-10802.

Verhoef, B.-E., Vogels, R., \& Janssen, P. (2012). Inferotemporal cortex subserves three-dimensional structure categorization. Neuron, 73(1), 171-182.

Whalen, P. J., Rauch, S. L., Etcoff, N. L., McInerney, S. C., Lee, M. B., \& Jenike, M. A. (1998). Masked presentations of emotional facial expressions modulate amygdala activity without explicit knowledge. The Journal of Neuroscience, 18(1), 411-418. 
Copyright of NeuroRehabilitation is the property of IOS Press and its content may not be copied or emailed to multiple sites or posted to a listserv without the copyright holder's express written permission. However, users may print, download, or email articles for individual use. 